\title{
Product Smartness and Use-Diffusion of Smart Products: The Mediating Roles of Consumption Values
}

\author{
Hyun Jung Park ${ }^{1} \&$ Hyung Seok Lee ${ }^{2}$ \\ ${ }^{1}$ International Business Department, Chungbuk National University, Cheongju, South Korea \\ ${ }^{2}$ Faculty of Business Administration, Chungbuk National University, Cheongju, South Korea \\ Correspondence: Hyung Seok Lee, Faculty of Business Administration, Chungbuk National University, 53 \\ Naesudong-ro Heungdeok-gu, Cheongju Chungbuk 361-763, South Korea. Tel: 82-43-261-3743. E-mail: \\ hyunglee@cbnu.ac.kr
}

Received: December 6, 2013 Accepted: December 18, 2013 Online Published: January 27, 2014

doi:10.5539/ass.v10n3p54 URL: http://dx.doi.org/10.5539/ass.v10n3p54

\begin{abstract}
This study proposes and tests the antecedent effects of product smartness on the consumption values using smart phones. The study also examines the relationship between consumers' value perception and use-diffusion. Results show that the six smartness dimensions have different impacts on each of the values. Multifunctionality and adaptability are the primary antecedents of functional value perception. Reactivity, humanlike interaction, multifunctionality and adaptability are positively related to perceived emotional value. Both functional and emotional values reinforce higher usage behavior as well as new usage behavior, thereby broadening the applicability of the technology. Consumption values mediate the relationships between some product smartness dimensions and the usage rate. Results also suggest that the smartness features that act as the primary drivers for intense usage are not the same features that drive the decision to use the product in various ways. The findings support the use of differentiated marketing strategies for the use-diffusion of each smart product.
\end{abstract}

Keywords: smart products, smart phones, product smartness, consumption values, use-diffusion

\section{Introduction}

Many products with digital properties called as smart or intelligent are in the market. These smart products are fundamentally changing both the competitive landscape for business and the daily lives of consumers. Given the technological evolution and the increasing adoption of smart products in the world, it becomes necessary to clarify why people use smart technologies for their everyday life and how product smartness dimensions affect consumers' perceptions or usage patterns. Despite the exponential growth of smart products and the fact that usage behaviors need to be carefully examined to fully reveal the diffusion story, there is little research on how or whether attributes of smart products provide perceived values that can enhance consumers' usage experiences.

This study proposes and tests the antecedent effect of product smartness on the consumption values of users. The article also examines the relationship between the value perceptions of consumers and the use-diffusion. The success of smart products not only depends on adoption decisions and the number of people that accept the technology, but relies at least as much on actual and sustained usage. The approach of this paper advances the smart product research and the value literature by increasing our understanding of how consumers' perceptions of smartness features and values influence their post-purchase behavior. Using smart phone users, this study identifies different roles of various smartness features related to consumption values and usage patterns. The findings support the use of differentiated value-based marketing strategies using smartness features.

\section{Theoretical Background and Hypothesis}

\subsection{Product Smartness}

The smart product definitions existing in literature cover different levels of smartness. Kintzig, Poulain, Privat, and Favennec (2003), for example, define smart object simply as a physical device equipped with a processor, memory, at least one network connection, and various sensors/actuators. Siegmund (2004) adds a specific dimension to this definition and defines a smart product as an "everyday object" consisting both from an everyday thing and information technology that augments it. In general, smart products are products that contain IT in the form of, for example, microchips, software and sensors, and that are therefore able to collect, process, 
and produce information (Rijsdijk \& Hultink, 2009). Smart phones, autonomous vacuum cleaners, sensor-based heating and lighting controllers, interactive TVs, car navigation systems are some of the examples easily available to consumers.

Product smartness consists of the dimensions of autonomy, adaptability, reactivity, multifunctionality, ability to cooperate, humanlike interaction, and personality. Rijsdijk and Hultink (2009) investigated whether these smartness dimensions, with the exception of humanlike interaction and personality, influence innovation attributes such as relative advantage, compatibility, observability, complexity and perceived risk. Higher levels of product smartness generally increased the perceived characteristics that determine an innovation's rate of adoption.

\subsection{Consumption Value}

A theoretical model of perceived value was developed by Sheth, Newman and Gross (1991), who regard consumer choice as a function of multiple dimensions of consumption value such as functional, emotional, conditional, epistemic, and social value. Functional value pertains to whether a product is able to perform its functional, utilitarian, or physical purposes. Emotional value is related to various affective states. Conditional value reflects that some market choices are contingent on the situation or set of circumstances faced by the consumers.

This study does not relate epistemic and social value to features of product smartness. Epistemic value is concerned with a desire for knowledge motivated by curiosity or the seeking of novelty, usually occurring in the early stage of adoption. Social value involves highly visible products or services to be shared with others. In smart products, the relation between product form and how it can be used is less obvious than in non-smart products. For example, a PDA can contain functionality such as a diary, calculator, and address book. This functionality is not communicated by the product's form (Rijsdijk \& Hultink, 2009).

\subsection{Use-Diffusion}

This paper investigates the paradigm of use-diffusion (UD) as consumption behavior, instead of the traditional adoption-diffusion (AD) paradigm. The adoption of innovative products is not the only object of the diffusion research, used degree of innovative product can be considered as an important variable of innovation diffusion degree.

Typically, the marketing literature on innovation diffusion has focused on the pre-adoption process. Few known studies explicitly examine consumers' post-adoption behavior. Shih and Venkatesh (2004) first proposed a so called use-diffusion model, which examines how an innovation is integrated into the household through usage behavior. The authors examined the respondents' PC and Internet uses in two dimensions, variety of use (number of applications) and rate of use (usage time) to measure degree of technology use, then classified the users into separate groups.

The decision to adopt a smart product differs from the post-adoption decision, which is the decision to utilize the adopted technology. Holbrook (2006) calls for researchers to explore the factors differentiating the drivers of initial adoption from those influencing continued use over time. This study explores the underlying motives or values that drive users to actually use smart products.

As little attention has been devoted to smart products, research on usage behavior related to these products is sparse. To explain consumer use of smart products, this study develops two research questions: 1) which product smartness factors play important roles in consumers' evaluation of consumption value, and 2) what are the consequences or usage patterns of such evaluation? Although the importance of perceived value in customer decision-making is well known, few studies empirically assess the direct effects of various perceived value dimensions on post-purchase behavior (Pihlström \& Brush, 2008). The direct effects of value dimensions on behavioral constructs have received limited attention. This study explores the benefits of six smartness attributes as antecedents of consumer evaluation of their current use of smart products. Outcome variables of perceived consumption values are the usage rate and variety of use, use-diffusion measures.

It is expected that the autonomy is mainly related to functionality because autonomous products such as autonomous lawn mowers or robot vacuum cleaners perform their tasks with less interference from the user. Driverless cars park themselves and some drivers use a mobile phone application to activate autonomous parking. Wi-Fi sensors in smart phones connect to wireless network infrastructure autonomously. Products with a high level of autonomy do not need human intervention but instead control themselves, which might explain the little relationship between autonomy and emotional value users tend to feel.

H1: Autonomy is likely to increase perceived functional value of smart products. 
Conversely, the ability to interact and communicate with the user in a natural, human way is likely to increase the perceived emotional value. Car navigation systems produce speech, and some of them also understand speech. Consumers could become attached to smart phones that offer humanlike interaction through voice recognition applications. Not only does Siri on Apple iPhone or iPad recognize our voice but it has a personality which makes the app addictive because we start to feel over time that we have a personal assistant who is our friend.

H2: Humanlike interaction is likely to increase perceived emotional value of smart products.

Ability to cooperate is the ability to form and join networks with other products. Computers can be attached to scanners, printers, musical instruments, video cameras, and so on. The utility derived from communication ability of a smart phone with a computer, for example, is a value dependent on the contexts in which users work on a computer. You can use your smart phone as a broadband modem for your laptop when needed. As conditional value applies to products that have a value strongly tied to use in a specific context, ability to cooperate may have a positive effect on the conditional value.

H3: Ability to cooperate is likely to increase perceived conditional value of smart products.

Reactivity and adaptability are about ability to sense context. While a reactive product merely responds to changes in its environment, an adaptable product improves the match between its functioning and its environment over time. As for reactivity, some washing machines signal if they are overloaded with laundry and vacuum cleaners select extraordinary large objects into a separate compartment. As for adaptability, your smart phone can make progress in addressing your unique needs for applications over time by recommending apps you might like based on your lists of downloaded apps. The ability to customize the functionality of a device to fit one's needs creates a personal meaning and emotional value. Multifunctionality refers to the phenomenon that a single product fulfills multiple functions. Smart phones incorporate multiple functions, including those of other devices such as the personal digital assistant (PDA), timer/alarm clock, GPS receiver/navigator, MP3 player, even laptop computer. Voice and text communication, images and maps, information search, music enjoyment, game playing and even alarm clock services converge in a single unit. These three features might fulfill consumer needs for the functional, emotional and conditional utility of smart products.

H4: Reactivity is likely to increase perceived functional, emotional, or conditional value of smart products.

H5: Adaptability is likely to increase perceived functional, emotional, or conditional value of smart products.

H6: Multifunctionality is likely to increase perceived functional, emotional, or conditional value of smart products.

The original theory of consumption values presented a narrow view in which the value components affected only consumption choice decisions. However, perceived value as a cognitive concept may influence many other behavioral outcomes, such as consumer satisfaction, behavioral usage intentions, and brand loyalty. Consumer value is a superordinate goal and consumer usage is a subordinate goal, as it is a behavioral intention. According to goal and action identity theories, a superordinate goal is likely to regulate subordinate goals (Yang and Peterson, 2004). Thus, consumer value regulates behavioral intentions as long as such relational exchanges provide superior value. Therefore, the theory may be extended to include behavioral outcome variables that go beyond mere purchase decisions.

H7: Functional value increases the rate of use or variety of use of smart products.

H8: Emotional value increases the rate of use or variety of use of smart products.

H9: Conditional value increases the rate of use or variety of use of smart products.

\section{Empirical Analysis}

\subsection{Data Collection and Measures}

This study uses 184 surveys out of 200 collected from undergraduate students at four Korean universities. Of the sample, $63.5 \%$ were $19-24$ years old and $26.5 \%$ were $25-40.63 .6 \%$ were male and $26.4 \%$ were female.

Each questionnaire item used a Likert-type response format ranging from 1, "strongly disagree," to 5 , "strongly agree." Rijsdijk and Hultink (2009) provide the measures for product smartness. Autonomy was measured by using three items: My smart phone takes the initiative, works independently, and does things by itself. Adaptability was measured by asking the respondents' agreement with three statements: My smart phone improves itself, acts on the basis of previously collected information, and delivers a better performance over time. Reactivity used three statements: My smart phone keeps an eye on its environment, directly adapts its behavior 
to the environment, and observes its environment. Multifunctionality measure used three items: My smart phone has multiple functions, performs multiple tasks, and fulfills multiple functional needs. Humanlike interaction was assessed by the respondents' agreement with the following items created for this study: My smart phone can communicate with me, and help me via voice recognition equipment. Ability to cooperate used three statements: My smart phone communicates with other devices, achieves a common goal in cooperation with other products, and can be attached to other products.

The scales of consumption values adapted from Sheth et al. (1991) were modified to be relevant to the smart phone usage context. Functional value used three items: Using this smart phone makes my life easier, is efficient way to manage my time, and come in handy. Emotional value was measured by asking the respondents' agreement with three statements: Using this smart phone gives me pleasure, makes me feel good, and makes me feel relaxed. Conditional value was assessed by the respondents' agreement with the following items: With the help of my smart phone I get what I need in a certain situation. My smart phone can be used wherever and whenever. My smart phone fulfills my urgent need for real-time information exchange.

Rate of use scales ask how long the respondent spends on the smart phone as well as how essential the product is for everyday life. Variety of use checks whether the subject uses the product in many ways. All items were validated through a pre-test procedure with 20 respondents to ensure the fulfillment of content validity.

To assess measurement validity, a confirmatory factor analysis was run for all the constructs in the model. The process analyzes the indicator reliability of all constructs by looking at the factor loadings; generally, items with loadings of less than 0.5 should be dropped. Convergent validity was tested by analyzing composite reliability (CR) and average variance extracted (AVE); recommended threshold values of 0.8 for CR and 0.5 for AVE. Finally, the Cronbach's alpha was examined for each construct based on the recommendation for a threshold alpha value of 0.7. According to the results of the present analysis, factor loadings, CR, AVE, and Cronbach's alpha indicate a high level of convergent validity.

Table 1. Measurement information

\begin{tabular}{llllll}
\hline Factor & $\begin{array}{l}\text { Number } \\
\text { of items }\end{array}$ & $\begin{array}{l}\text { Range } \\
\text { loadings }\end{array}$ & $\begin{array}{l}\text { of } \\
\text { Cronbach's } \\
\text { alpha }\end{array}$ & $\begin{array}{l}\text { Average } \\
\text { variance } \\
\text { extracted }\end{array}$ & $\begin{array}{l}\text { Composite } \\
\text { reliability }\end{array}$ \\
\hline Autonomy & 3 & $0.74-0.93$ & 0.86 & 0.69 & 0.88 \\
Reactivity & 3 & $0.66-0.95$ & 0.88 & 0.74 & 0.92 \\
Adaptability & 3 & $0.69-0.78$ & 0.76 & 0.52 & 0.81 \\
Multifunctionality & 3 & $0.68-0.95$ & 0.80 & 0.62 & 0.89 \\
Humanlike interaction & 2 & $0.76-0.96$ & 0.85 & 0.75 & 0.84 \\
Ability to cooperate & 3 & $0.77-0.92$ & 0.86 & 0.70 & 0.87 \\
Functional value & 3 & $0.68-0.89$ & 0.79 & 0.58 & 0.86 \\
Emotional value & 3 & $0.81-0.90$ & 0.89 & 0.75 & 0.92 \\
Conditional value & 3 & $0.71-0.88$ & 0.81 & 0.60 & 0.89 \\
Rate of use & 2 & $0.80-0.93$ & 0.81 & 0.76 & 0.82 \\
Variety of use & 1 & - & - & - & - \\
\hline
\end{tabular}

Discriminant validity was tested by means of the criterion proposed by Fornell and Larcker (1981). The results support discriminant validity because, for every pair of factors, the squared correlation between them is below the two values of average variance extracted. Table 2 shows a factor correlation matrix. 
Table 2. Correlations, means, standard deviations, and average variance extracted ${ }^{\mathrm{a}}$

\begin{tabular}{lllllllllllll}
\hline Construct & Mean & S.D. & 1 & 2 & 3 & 4 & 5 & 6 & 7 & 8 & 9 & 10 \\
\hline 1.Autonomy & 2.73 & 0.86 & $\mathbf{0 . 8 3}$ & & & & & & & & & \\
2.Reactivity & 3.00 & 0.75 & 0.25 & $\mathbf{0 . 8 6}$ & & & & & & & & \\
3.Adaptability & 3.57 & 0.72 & 0.25 & 0.49 & $\mathbf{0 . 7 2}$ & & & & & & & \\
4.Multifunctionality & 4.23 & 0.64 & 0.00 & 0.32 & 0.42 & $\mathbf{0 . 7 9}$ & & & & & & \\
5.Humanlike & 3.30 & 1.00 & 0.32 & 0.13 & 0.13 & 0.09 & $\mathbf{0 . 8 7}$ & & & & & \\
interaction & & & & & & & & & & & & \\
6.Ability to cooperate & 3.77 & 0.89 & 0.12 & 0.15 & 0.38 & 0.29 & 0.23 & $\mathbf{0 . 8 4}$ & & & & \\
7.Functional value & 3.90 & 0.69 & 0.08 & 0.22 & 0.40 & 0.53 & 0.11 & 0.23 & $\mathbf{0 . 7 6}$ & & & \\
8.Emotional value & 3.73 & 0.78 & 0.10 & 0.34 & 0.38 & 0.53 & 0.17 & 0.23 & 0.68 & $\mathbf{0 . 8 7}$ & & \\
9.Conditional value & 4.21 & 0.62 & 0.00 & 0.12 & 0.10 & 0.30 & 0.05 & 0.28 & 0.56 & 0.40 & $\mathbf{0 . 7 7}$ & \\
10.Rate of use & 3.21 & 1.07 & 0.21 & 0.24 & 0.26 & 0.18 & 0.02 & 0.08 & 0.53 & 0.62 & 0.29 & $\mathbf{0 . 8 7}$ \\
11.Variety of use & 3.25 & 0.96 & 0.12 & 0.15 & 0.22 & 0.18 & 0.02 & 0.05 & 0.25 & 0.33 & 0.12 & 0.36 \\
\hline
\end{tabular}

${ }^{\mathrm{a}}$ Diagonal elements (in bold) are square roots of the average variance extracted (AVE) values and off-diagonal numbers are correlations between variables in this study.

Table 3. Estimated path coefficients

\begin{tabular}{llll}
\hline Construct & Functional value & Emotional value & $\begin{array}{l}\text { Conditional } \\
\text { value }\end{array}$ \\
\hline Autonomy $\rightarrow$ Value & 0.02 & - & - \\
Reactivity $\rightarrow$ Value & -0.01 & $0.14^{* *}$ & 0.04 \\
Adaptability $\rightarrow$ Value & $0.17^{* *}$ & $0.16^{* *}$ & -0.09 \\
Multifunctionality $\rightarrow$ Value & $0.49^{* *}$ & $0.65^{* *}$ & $0.31^{* *}$ \\
Humanlike interaction $\rightarrow$ Value & - & $0.22^{*}$ & - \\
Ability to cooperate $\rightarrow$ Value & - & - & $0.16^{* *}$ \\
\hline Functional value $\rightarrow$ Rate of use & $0.51^{* *}$ & & \\
Emotional value $\rightarrow$ Rate of use & $0.67^{* *}$ & & \\
Conditional value $\rightarrow$ Rate of use & 0.02 & & \\
Functional value $\rightarrow$ Variety of use & $0.41^{*}$ & & \\
Emotional value $\rightarrow$ Variety of use & $0.29^{*}$ & & \\
Conditional value $\rightarrow$ Variety of use & -0.11 & & \\
\hline${ }^{*} \mathrm{p}<0.05,{ }^{* *} \mathrm{p}<0.001$ & & &
\end{tabular}

\subsection{Analysis Results}

A structural equation modeling technique was used to analyze the data and test the model. The ratio of chi-square to degrees of freedom was 1.82 , which met the recommended criteria of less than 3 . The goodness of fit index (GFI) was 0.90 , and root mean square error of approximation (RMSEA) was 0.06 , respectively. A comparison of these overall fit indices of the structural model against those recommended in the literature indicates that the hypothesized model is a good representation of the structures underlying the observed data (Baumgartner \& Homburg, 1996).

The results of hypothesis testing are summarized in Table 3. Except for the effect of autonomy or reactivity on the functional value and the effect of reactivity or adaptability on the conditional value, all coefficients of smartness are significant at the $\mathrm{p}<0.05$ level.

Autonomy has little impact on the perceived functional value. This finding is in line with the results of the study 
by Rijsdijk and Hultink (2003), wherein the authors evaluated consumer perceptions of autonomous products and found that consumers perceive products with higher levels of autonomy as more difficult to understand and use than products with lower levels of autonomy.

Multifunctionality is the most influential factor when consumers evaluate all of the perceived consumption values. Offering so many useful tools in one product, accessible as needed, makes the smart phone functional. The ability to access social networks sites, for example, enables users to maintain their social relationships increasing emotional value. Smart phones provide constant access to email and the internet wherever a person happens to be increasing conditional value.

Adaptability affects both functional and emotional value. While humanlike interaction and reactivity help fulfill emotional value, ability to cooperate increases the conditional value of smart phones.

With respect to usage behaviors, functional value is significant in raising both usage rate $(\beta=0.51, p<0.001)$ and variety of use $(\beta=0.41, p<0.05)$; Emotional value is also positively related to both rate of use $(\beta=0.67, p$ $<0.001)$ and variety of use $(\beta=0.29, \mathrm{p}<0.05)$. This finding suggests that users who perceive high functional value tend to develop a broader variety of use as well as usage rate. Emotional value may not be a defining driver of usage variety, but becomes a very important factor for raising usage rate.

Table 4. Mediating effects of consumption values

\begin{tabular}{|c|c|c|c|c|}
\hline \multicolumn{5}{|c|}{ Dependent variable $=$ Rate of use } \\
\hline \multicolumn{2}{|l|}{ Mediation variable } & Adaptability & Multifunctionality & Reactivity \\
\hline \multirow{6}{*}{ Emotional value } & 1 stage (beta1) & $0.35^{* *}$ & $0.61^{* *}$ & $0.32^{* *}$ \\
\hline & 2 stage (beta2) & $0.33^{* *}$ & $0.40^{* *}$ & $0.39^{* *}$ \\
\hline & 3 stage-independent (beta3) & 0.04 & -0.14 & 0.13 \\
\hline & 3stage-mediating (beta4) & $0.82^{* *}$ & $0.89^{* *}$ & $0.79^{* *}$ \\
\hline & & full & full & full \\
\hline & Mediation ertects & mediating & mediating & mediating \\
\hline \multirow{7}{*}{ Functional value } & & Adaptability & Multifunctionality & \\
\hline & 1 stage & $0.34^{* *}$ & $0.51^{* *}$ & \\
\hline & 2 stage & $0.33^{*}$ & $0.40^{* *}$ & \\
\hline & 3 stage-independent & 0.10 & 0.05 & \\
\hline & 3 stage-mediating & $0.68^{* *}$ & $0.69^{* *}$ & \\
\hline & Mediation effects & full & full & \\
\hline & ivedratuon entists & mediating & mediating & \\
\hline \multirow{6}{*}{ Conditional value } & & Reactivity & Ability to cooperate & \\
\hline & 1 stage & $0.34^{* *}$ & $0.18^{* *}$ & \\
\hline & 2 stage & $0.40^{* *}$ & 0.11 & \\
\hline & 3 stage-independent & $0.26^{* *}$ & 0.02 & \\
\hline & 3 stage-mediating & $0.42^{* *}$ & $0.51^{* *}$ & \\
\hline & Mediation effects & $\begin{array}{l}\text { partial } \\
\text { mediating }\end{array}$ & - & \\
\hline
\end{tabular}

${ }^{*} \mathrm{p}<0.05,{ }^{* *} \mathrm{p}<0.001$

For additional analysis, Baron and Kenny's (1986) causal-steps test was conducted for determining mediation effects of consumption values. Table 4 indicates that emotional value fully mediates the relationship between some of product smartness dimensions including adaptability, multifunctionality, reactivity, and rate of use. Functional value also mediates the relationship between adaptability or multifunctionality and rate of use. Conditional value is a partial mediator of the reactivity - rate of use relationship. The main effect of reactivity on 
the rate of use became lower in magnitude in the regression equation that controlled for conditional value than the coefficients obtained from the regression equations that excluded conditional value. As a regression coefficient representing the effect of ability to cooperate on rate of use is insignificant, the last mediation is not possible or likely.

\section{Discussion and Conclusion}

This paper examines the use diffusion of smart products, smart phones in particular, through the model of consumption values in order to deepen the insight on how consumers perceive and use smart products. By viewing smart phone use as smart product consumption, this study explores the relationships among perceived smartness, perceived value, and usage behavior within the context of consumers' current usage of smart phones. Relatively little is known about how people perceive smartness features and consumption values of smart products, which is an important antecedent of usage pattern. Evidence for the product smartness effect therefore is important not only for establishing the link between smartness features and consumption values but also for demonstrating that consumption values can affect how consumers use the product, subsequently influencing consumers' post-purchase consumer behavior.

The six smartness dimensions have different impacts on each of the values. With respect to functional utility, multifunctionality and adaptability become the primary antecedents of the value perception. For experiential utility, reactivity and humanlike interaction as well as multifunctionality and adaptability are positively related to the perceived emotional value. By collecting functionality together in one platform, each smart phone acts as a highly valuable portfolio in the hands of each particular user.

In this data set, functional and emotional values reinforce higher usage behavior as well as new usage behavior, thereby broadening the applicability of the technology. Accordingly, the participants who find great utility tend to use their smart phones in various ways. Although three values have a somewhat limited effect on the use-diffusion by primarily increasing the rate of use, the values certainly mediate the relationships between some product smartness dimensions and the usage rate. These results suggest that the smartness features that act as the primary drivers for intense usage are not the same features that drive the decision to use the product in various ways.

The present research facilitates insights on the subjective perceptions consumers regarding the values of smart product usage, and helps us to better understand how smartness-related marketing might enhance these values. The current study is not without limitations, however. One cannot generalize the results of this study easily beyond the present product category. Follow-up studies using various smart products such as autonomous vacuum cleaners, sensor-based heating and lighting controllers, interactive TVs, car navigation systems would be helpful to reconfirm the findings. In addition, product smartness dimensions could make varying contributions to increasing consumption values in different usage situations. Future research should include other product attributes, such as brand and price, characteristics of adopters, or differing contexts for product usage to increase the validity of the findings.

This is only a first step in the important process of understanding the nature of relationship between product smartness and use-diffusion of smart products. Gaining a comprehensive understanding of the drivers of smart products usage will help engineers and marketers to develop effective strategies that meet consumer needs for smart products.

\section{Acknowledgement}

This work was supported by the research grant of the Chungbuk National University in 2013.

\section{References}

Baron, R. M., \& Kenny, D. A. (1986). Moderator-mediator variables distinction in social psychological research: Conceptual, strategic, and statistical considerations. Journal of Personality and Social Psychology, 51(6), 1173-1182. http://dx.doi.org/10.1037/0022-3514.51.6.1173

Baumgartner, H., \& Homburg, C. (1996). Applications of structural equation modeling in marketing and consumer research: A review. International Journal of Research in Marketing, 13(2), 139-161. http://dx.doi.org/10.1016/0167-8116(95)00038-0

Bhattacherjee, A. (2001). Understanding information systems continuance: An expectation-confirmation model. MIS Quarterly, 25(3), 351-370. http://dx.doi.org/10.2307/3250921

Fornell, C., \& Larcker, D. (1981). Evaluating structural equation models with unobservable variables and measurement error. Journal of Marketing Research, 18(1), 39-50. http://dx.doi.org/10.2307/3151312 
Holbrook, M. B. (2006). Consumption experience, customer value, and subjective personal introspection: An illustrative photographic essay. Journal of Business Research, 59, 714-725. http://dx.doi.org/10.1016/j.jbusres.2006.01.008

Kintzig, C., Poulain, G., Privat, G., \& Favennec, P. N. (2003). Communicating with smart objects: Developing technology for usable pervasive computing systems. London: Kogan Page.

Pihlström, M., \& Brush, G. J. (2008). Comparing the perceived value of information and entertainment mobile services. Psychology and Marketing, 58(8), 732-755. http://dx.doi.org/10.1002/mar.20236

Rijsdijk, S. A., \& Hultink, E. J. (2003). Honey, have you seen our hamster? Consumer evaluations of autonomous domestic products. Journal of Product Innovation Management, 20, 204-216. http://dx.doi.org/10.1111/1540-5885.2003003

Rijsdijk, S. A., \& Hultink, E. J. (2009). How today's consumers perceive tomorrow's smart products. Journal of Product Innovation Management, 26(1), 24-42. http://dx.doi.org/10.1111/j.1540-5885.2009.00332.x

Sheth, J. N., Newman, B. I., \& Gross, B. L. (1991). Why we buy what we buy: A theory of consumption values. Journal of Business Research, 22, 159-170. http://dx.doi.org/10.1016/0148-2963(91)90050-8

Shih, C. F., \& Venkatesh, A. (2004). Beyond adoption: Development and application of a use-diffusion model. Journal of Marketing, 68(1), 59-72. http://dx.doi.org/10.1509/jmkg.68.1.59.24029

Siegemund, F. (2004). Cooperating smart everyday objects - exploiting heterogeneity and pervasiveness in smart environments, PhD Dissertation, Swiss Federal Institute of Technology, Zurich.

Yang, Z., \& Peterson, R. T. (2004). Customer perceived value, satisfaction, and loyalty: The role of switching costs. Psychology \& Marketing, 21(10), 799-822. http://dx.doi.org/10.1002/mar.20030

\section{Copyrights}

Copyright for this article is retained by the author(s), with first publication rights granted to the journal.

This is an open-access article distributed under the terms and conditions of the Creative Commons Attribution license (http://creativecommons.org/licenses/by/3.0/). 